\title{
Low Calcium Intake and Hypovitaminosis D Negatively Affect Oral Health in Young Men
}

\begin{abstract}
Antonenko $\mathrm{O}^{1}$, Seijo $\mathrm{M}^{1}$, Brito $\mathrm{G}^{2}$, Gualtieri $\mathrm{AF}^{3}$, Pellegrini $\mathrm{G}^{1,2}$ and Zeni $\mathrm{SN}^{1,2 *}$

${ }^{1}$ Metabolic Bone Diseases Laboratory, Clinical Hospital, Immunology, Genetic and Metabolism Institute (INIGEM), National Council for Scientific and Technologic Research (CONICET), Buenos Aires University (UBA), Argentina

${ }^{2}$ Department of General and Oral Biochemistry, School of Dentistry, Buenos Aires University (UBA), Argentina ${ }^{3}$ Department of Biophysics, School of Dentistry, Buenos Aires University (UBA), Argentina

*Corresponding author: Susana N Zeni, General and Oral Biochemistry Department, School of Dentistry, Buenos Aires University (UBA), Av. Córdoba 2351-8vo Piso (1120) Buenos Aires, Argentina
\end{abstract}

Received: October 06, 2017; Accepted: November 08, 2017; Published: December 07, 2017

\begin{abstract}
Aim: Oral health and nutrition have a synergistic bidirectional relationship. Diet plays an important role in dental caries process, one of the main factors associated with high risk of tooth loss in adults. Conversely, tooth loss, pain and discomfort limit food choices which negatively affect nutritional status. The objective was to evaluate association between oral health and calcium ( $\mathrm{Ca}$ ) and vitamin D nutritional status, several dietary and life-style habits in young men.
\end{abstract}

Materials and Methods: A total of 241 men (29.4 \pm 2.1 years) were studied. Ca intake (Cal) and protein intakes were recorded, and 25hydroxyvitamin D $(250 H D)$ was determined. Dental status and caries risk were assessed by Decayed (D), Missing (M) and Filled (F) Teeth, (DMFT) index, Löe Silness Plaque Index (PI) and sugar intake (SI). Results: Deficient Cal was observed in $48 \%$ of men; $71 \%$ had $250 \mathrm{HD}<30 \mathrm{ng} / \mathrm{mL}$ and $65 \%$ consumed soft drinks daily. $\mathrm{M} / \mathrm{T}$ was $2.9 \%$; $\mathrm{D} / \mathrm{T}$ was $16.2 \%$ and $\mathrm{F} / \mathrm{T}$ was $18.7 \% ; 41 \%$ were missing at least one tooth. DMFT score was $11.4 \pm 0.9, \mathrm{PI}$ and $\mathrm{SI}$ were $1.9 \pm 0.2$ and $5.3 \pm 0.2$, respectively. Adjusted-Cal by risk factors was associated with higher caries activity $(p<0.01)$ and missing teeth $(p<0.013) ; 100 \%$ presented gingivitis. DMFT of the one third of men with the highest caries scores reached $17.4 \pm 0.5$; these men had significantly lower $\mathrm{Cal}(p<0.023)$ and higher daily consumption of soft drinks and PI values $(p<0.05)$.

Conclusion: $\mathrm{Cal}$ and vitamin $\mathrm{D}$ inadequacies, together with certain dietary and lifestyle habits observed in the studied men would seemingly be responsible, at least in part, for their high cariogenic activity.

Keywords: Low calcium intake; Hypovitaminosis D; Oral health; Young men

\section{Abbreviations}

BAP: Bone Alkaline Phosphatase; BMD: Bone Mineral Density; BMI: Body Mass Index; BW: Body Weight; Ca: Calcium; CaI: Ca Intake; CI: Confidence Intervals; Creat: Creatinine; CS: Chemical Score; CTX: Carboxi-Terminal Telopeptide of Type I Collagen; CV: Coefficient of Variation; D: Decayed; DMFT: Decayed, Missing, Filled and Teeth; EAR: Estimated Average Recommendations; ELISA: Enzyme-Linked Immune-Absorbent Assay; ENNyS: National Survey on Nutrition and Health; EPS: Extracellular Polysaccharides; F: Filled; M: Missing; NHANES: National Health and Nutrition Examination Survey; P: Phosphate; PI: Plaque Index; PTH: Parathyroid Hormone; RDA: Recommended Dietary Allowance; SD: Standard Deviation; SI: Sugar Intake; Sic: Significant Caries Index; T: Teeth; UBA: University of Buenos Aires; WHO: World Health Organization; 25OHD: 25hydroxyvitamin D

\section{Introduction}

Diet plays an important role in the dental caries process, one of the main factors associated with high risk of tooth loss in adults. In this regard, several studies have reported an inverse association between the consumption of certain nutrients and progressively impaired oral health [1]. In turn, tooth loss, pain and discomfort impose dietary restrictions because they reduce the ability to masticate, and consequently limit food choices, with negative consequences on nutritional status. Both tooth loss and compromised diet contribute to creating a vicious circle that would seemingly increase dental caries [2-4]. The World Health Organization (WHO) has acknowledged that oral health and nutrition have a synergistic bidirectional relationship, and have included dental disease among the chronic diseases that can be prevented by diet [5].

Certain dietary habits are associated with positive or negative effects on oral health. Milk and dairy product consumption is recognized as one of the factors that decreases caries development [6]. These products are the major source of calcium $(\mathrm{Ca})$ and phosphate (P), both of which have beneficial effects on dental plaque and saliva. In this regard, a high concentration of $\mathrm{Ca}$ and $\mathrm{P}$ may decrease the adherence of caries-associated bacteria to the enamel [7], whereas high $\mathrm{Ca}$ intake may increase enamel remineralization, decrease demineralization, prevent alveolar bone loss, and, hence, promote dental health $[8,9]$. Vitamin D could also influence oral health, protecting against periodontal disease progression and, consequently, against alveolar bone loss. This is because of the direct effect of vitamin $\mathrm{D}$ on bone and phospho-calcium homeostasis and its antiinflammatory and antimicrobial actions [10]. It is important to point out that $\mathrm{Ca}$ and vitamin $\mathrm{D}$ insufficiency/deficiency is a prevalent condition in the general population, including adolescents and young adults [11-13].

It is now recognized that there has been a displacement of milk
Austin J Dent - Volume 4 Issue 7 - 2017

ISSN : 2381-9189 | www.austinpublishing group.com

Zeni et al. (C) All rights are reserved
Citation: Antonenko O, Seijo M, Brito G, Gualtieri AF, Pellegrini G and Zeni SN. Low Calcium Intake and Hypovitaminosis D Negatively Affect Oral Health in Young Men. Austin J Dent. 2017; 4(7): 1093. 
Table 1: General characteristics and biochemical parameters of the studied young men $(n=241)$.

\begin{tabular}{|c|c|c|}
\hline Studied parameters & Reference values & Subject's results Mean (SD) \\
\hline \multicolumn{3}{|l|}{ Anthropometry } \\
\hline Age (years) & & $29.4(2.1)$ \\
\hline Weight (kg) & & $70.9(1.9)$ \\
\hline Height (cm) & & $172.9(1.8)$ \\
\hline BMI $\left(k g / m^{2}\right)$ & & $23.5(1.1)$ \\
\hline \multicolumn{3}{|l|}{ Biochemical parameters } \\
\hline Serum calcium (mg/dl) & $8.9-10.4$ & $9.6 \pm 0.2$ \\
\hline Serum phosphorus (mg/dl) & $2.8-4.5$ & $3.8 \pm 0.3$ \\
\hline Parathormone (pg/mL) & $18.0-62.0$ & $41.3 \pm 5.0$ \\
\hline Bone Alkaline Phosphatase (UI/L) & $31-95$ & $71 \pm 6$ \\
\hline C-terminal telopeptide of collagen type I (CTX) (pg/mL) & $115-748$ & $626 \pm 82$ \\
\hline Urinary Calcium/Creatinine ratio (ng/mL) & $<0.11$ & $0.066 \pm 0.008$ \\
\hline \multicolumn{3}{|l|}{ Nutritional parameters } \\
\hline Calcium Intake (mg/day) & $>800$ & $619.4[432.5 ; 809.1]$ \\
\hline 25hydroxyvitamin D (25HOD)(ng/mL) & $>30-60$ & $25.3 \pm 1.9$ \\
\hline Protein Intake (g/day) & $>60$ & $70.2[46.4 ; 81.7]$ \\
\hline Protein Intake (g/kg/day) & $0.66-1.30$ & $1.06[0.67 ; 1.35]$ \\
\hline
\end{tabular}

Data were expressed as mean \pm SD or median [range] according to normality.

intake for soft drinks consumption, especially in adolescents and young adults $[14,15]$. A high consumption of soft drinks has negative effects on dental health, causing dental caries and enamel erosion [16]. Moreover, lifestyle habits such as poor oral hygiene, smoking or infrequent dental visits could results in an increase in cariogenic activity, which is one of the main risk factors of tooth loss [17]. It is known that men brush their teeth less often, visit the dentist for preventive purposes less frequently, and are less concerned with the preservation of their natural dentition than women [18].

We hypothesized that a poor oral health is associated with a low $\mathrm{Ca}$ intake and hypovitaminosis D in young men, and that certain dietary and life-style habits could influence such association. On these bases, the purpose of the present cross-sectional study was to evaluate bone resorption and oral health in relation to $\mathrm{Ca}$ and vitamin D nutritional status in a group of young-adult men. The effects of fruits and soft drinks and type and frequency of sugar consumption on caries progression were also explored.

\section{Sulbjects and Methods}

This cross-sectional, observational study was conducted in healthy young men studying or working at the University of Buenos Aires University (UBA) during 2010 and 2014. The study plan was approved by the Ethics Committee and the Teaching and Research Committee of the "José San Martín" Clinical Hospital, UBA. All procedures were carried out in keeping with the ethical and legal requirements based on the Nuremberg Code, Declaration of Helsinki and its amendments [19].

\section{Subjects}

Inclusion criteria: Healthy young adult men with no a history of previous bone fractures.

Exclusion criteria: Men that suffer any diseases or disorders that influence bone and phosphocalcium metabolism (i.e. diabetes, malignancies, chronic renal or liver disease, malabsorption syndromes, or hypercalcemia owing to primary hyperparathyroidism) or take dietary supplements or medications known to affect bone homeostasis (i.e., oral corticosteroids, fluoride, vitamin $\mathrm{D}$, calcitonin or bisphosphonates) were excluded. In addition, men who received vitamin $\mathrm{D}$ or $\mathrm{Ca}$ supplements, oral corticosteroids, fluoride, bisphosphonates, or any other medication that could affect bone metabolism were also excluded.

A total of 524 men were invited to participate; 251 men $(30.1 \pm 1.9$ years) agreed to be interviewed; 10 of them were excluded of the study based on the exclusion criteria. The final studied population comprised 241 men (29.4 \pm 2.1 years). All participants were previously informed of the aims of the study, and gave their written informed consent.

Lifestyle questionnaire: All the subjects completed a comprehensive non-validated lifestyle questionnaire based in Short Form 36 (Supplemental Table 1) [20,21]. It included questions about outdoor activities, smoking habits, occupation, and family history of fractures.

Anthropometrical analysis: Height and body weight (BW) were determined on the day of the first health examination. Height (m) was measured without shoes, using a calibrated metric scale graduated to the nearest $0.1 \mathrm{~cm}$. BW $(\mathrm{kg})$ was measured with a weighing scale graduated to the nearest $0.1 \mathrm{~kg}$. Body mass index (BMI) was calculated as follows: $\mathrm{BMI}=\mathrm{BW}\left(\mathrm{Kg} / \mathrm{m}^{2}\right)$. The Body Mass Index Classification of the WHO was used to define normal weight (BMI: 18.50-24.99); overweight (BMI: 25.00-29.99) and obesity (BMI $\geq 30$ ) [22].

Nutrient analysis: All participants received verbal and written instructions on how to record their daily food consumption on a semi quantitative food frequency questionnaire. All the questionnaires 
Table 2: Descriptive values of Decayed (D), Missing (M) and Filling (F) index (DMFT) and, D and M component as percentage of total teeth; Significant Caries Index (Sic), Plaque Index Löe Silness (PI) and Sugar Intake (SI) of the studied young men $(n=241)$

\begin{tabular}{|l|c|}
\hline Dental status evaluation & Subject's values Mean (SD) \\
\hline D (DMFT) & $4.8(0.5)$ \\
\hline M (DMFT) & $2.5(0.3)$ \\
\hline F (DMFT) & $5.5(0.5)$ \\
\hline DMFT & $11.4(0.9)$ \\
\hline SiC & $17.4(0.5)$ \\
\hline D/ Total \% & $16.2(2.0)$ \\
\hline M/Total\% & $2.9(0.7)$ \\
\hline F/Total\% & $18.7(1.9)$ \\
\hline PI & $1.9(0.2)$ \\
\hline SI (times/day) & $5.3(0.2)$ \\
\hline
\end{tabular}

were checked by the same dietician to avoid inter observer errors. $\mathrm{Ca}$ intake $(\mathrm{CaI})$ and protein intake were calculated according to the Argentinean Table of Food Consumption. Ca adequacy was determined according to the Estimated Average Recommendations (EAR) as follows: adequacy: $\mathrm{CaI} \geq 800 \mathrm{mg} / \mathrm{d}$; insufficiency: 600 $<\mathrm{CaI}<800 \mathrm{mg} / \mathrm{d}$; deficiency: $\mathrm{CaI} \leq 600 \mathrm{mg} / \mathrm{d}$ [23]. Protein nutritional status was determined according to the EAR of $0.66 \mathrm{~g} / \mathrm{kg} \mathrm{BW} /$ day of a protein with good digestibility and a high chemical score (CS) [23]. The Ca to Protein intake ratio $(\mathrm{mg} / \mathrm{g})$ was calculated.

The study was done between the end of August and the 15th of September to evaluated vitamin D status when sunshine is minimal. Vitamin D nutritional status was evaluated according to 25hydroxyvitamin D (25OHD) levels, a good index of vitamin D status, as follows: sufficiency $\geq 30 \mathrm{ng} / \mathrm{mL}$; insufficiency: $21-29 \mathrm{ng} / \mathrm{mL}$, and deficiency: $\leq 20 \mathrm{ng} / \mathrm{mL}$ [11]. This classification was used because although the Institute of Medicine's summary conclusions of vitamin $\mathrm{D}$ deficiency in relation to bone health reviewed that "practically all persons are sufficient at serum $25 \mathrm{OHD}$ levels of at least $20 \mathrm{ng} / \mathrm{mL}$ ( 50 nmol/L)" [23], the relevance of these specific cut points is less clear for some of the other known non classical actions of vitamin D (e.g., ant-inflammatory properties) [24].
Daily consumption of sugary alcoholic or non-alcoholic drinks (wine, sodas, fruit drinks or other high sugar beverages), fruit and vegetables were also evaluated.

Smokers were classified as light smokers ( $\leq 10$ cigarettes/day) or heavy smokers (>10 cigarettes/day).

Clinical assessment Patient dental and medical records were filled in. Dental examination was performed under appropriate lighting conditions and a dental chart was completed according to WHO recommendations [25]. The Decayed (D), Missing (M) and Filled (F) Teeth (DMFT) index was calculated to determine the prevalence and severity of dental caries [10]. The DMF index is a standard method for assessing dental caries experience in populations. Studies reported in the literature suggest a DMFT score $<3$ as indicative of low prevalence and severity of dental caries in 12-year-olds 23. The mean DMFT of the third of the population of young men with the highest caries score was calculated to assess severity of dental caries, as measured by the Significant Caries Index (Sic) [26].

Tooth loss was assessed based on component $\mathrm{M}$ of the DMFT index, and expressed as a percentage of total teeth $(\mathrm{M} / \mathrm{T})$. The presence of caries was evaluated according to component $\mathrm{D}$ and the percentage of teeth affected by caries was calculated $(D / T)$.

The accumulation of plaque due to improper brushing and flossing of teeth was recorded using the Löe Silness Plaque Index (PI) and marked with a score from 0 to 3 [27]. Carries risk was assessed based on frequency of sugar intake (SI), considering a value of SI $\leq$ 4 as absence of cariogenic risk and SI $>4$ as presence of cariogenic risk [28]. Oral hygiene and use of fluoride were also analyzed. Dental status of all the men was diagnosed by the same trained dentist to avoid differences among operators.

Biochemical analysis: Fasting blood samples were collected between 8:00 and 10:00 am between the 15th of May and 15th of July when sunshine is low. Samples were centrifuged and the serum was stored frozen at $-18^{\circ} \mathrm{C}$ until analyses were performed as previously published [2]. Fasting second void-urine samples were collected, acidified, and stored in a refrigerator at $4^{\circ} \mathrm{C}$ until analyses were performed.

Table 3: Mean values of serum levels of 24hydroxivitamin D (25HOD), Calcium (sCa), Phosphorus (sP), Bone Alkaline Phosphatase (BAP) and urinary calcium/ creatinine ratio (uCa/Creat) according to Ca intake and $25 \mathrm{HOD}$ levels in the studied men( $\mathrm{n}=241)$.

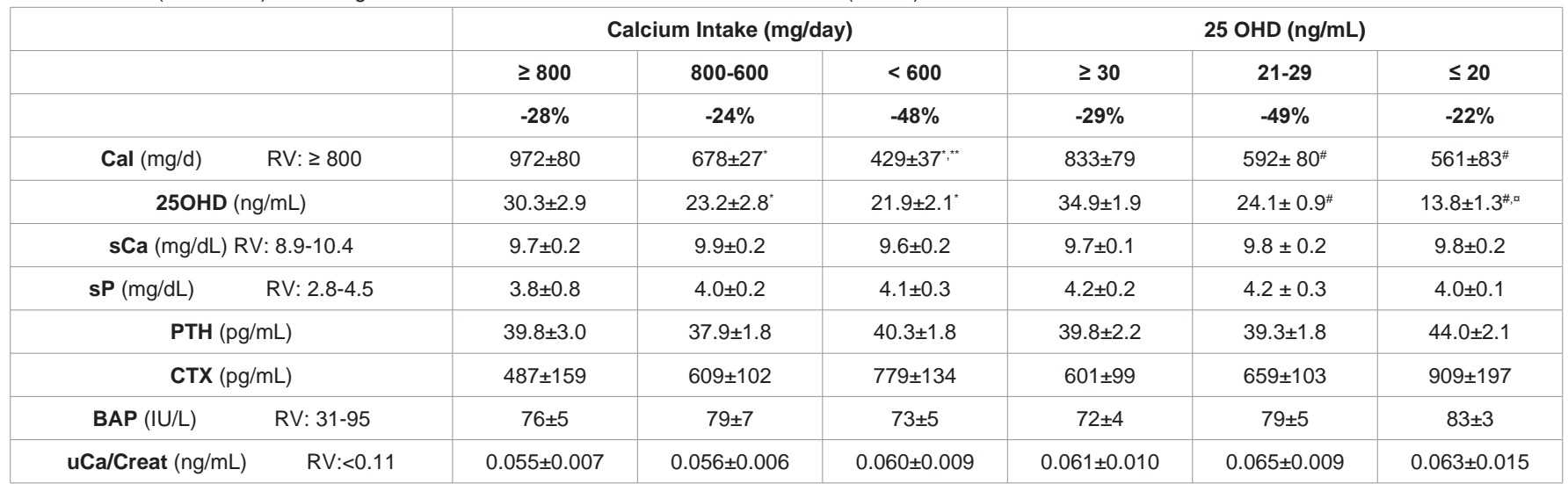

Data were expressed as mean \pm SD. They were analyzed by ANOVA two factors and Multiple Comparison tests as a post hoc test: " $p<0.05$ compared to Cal intake $>$ $800 \mathrm{mg} /$ day; ${ }^{* *} \mathrm{p}<0.05$ compared to Ca intake $800-600 \mathrm{mg} / \mathrm{day} ;{ }^{*} \mathrm{p}<0.05 \mathrm{compared}$ to levels of $25 \mathrm{OHD}>30 \mathrm{ng} / \mathrm{mL}$; ${ }^{\mathrm{p}} \mathrm{p}<0.05 \mathrm{compared}$ to levels of $25 \mathrm{OHD} 21-29 \mathrm{ng} / \mathrm{mL}$. 
Serum and urinary Ca were determined by atomic absorption spectrophotometry at $423 \mathrm{~nm}$, using lanthanum chloride as interference suppressor. Intraassay and intra-assay coefficient of variation $(\mathrm{CV})$ were $0.9 \%$ and $1.2 \%$, respectively. Serum phosphorus (P) was determined by UV-visible colorimetric method, using a commercial kit (Wiener SA). Sensitivity: $0.62 \mathrm{mg} / \mathrm{dL}$ Intraassay and intra-assay CV were $0.5-0.5 \%$ and $0.3-0.6 \%$, respectively. The $25 \mathrm{OHD}$ level was determined by competitive protein binding assay based on the use of radiolabeled ligands (ELISA, DiaSorin, RIA). Intraassay CV was $8.6-12.5 \%$, and intra-assay CV was $8.2-11.0 \%$. Sensitivity was $\leq$ $1.50 \mathrm{ng} / \mathrm{mL}$. Bone alkaline phosphatase (BAP) was determined by a colorimetric method, using a commercial kit (Boehringer Mannheim, Germany) that evaluates the activity of total BAP after bone isoform precipitation with wheat germ lectin. Cross-reactivity with liver isoform was less than $5 \%$. Sensitivity was $0.7 \mathrm{IU} / \mathrm{L}$. Intraassay and intra-assay CV were $4-5 \% \%$ and 6-8\%, respectively. Levels of carboxiterminal telopeptide of type I collagen (CTX) were measured by an enzyme-linked immune-absorbent assay (ELISA) (Nordic Bioscience Diagnostics A/S) with an intraassay CV of 6\%. Sensitivity was $6.0 \mathrm{pg} /$ $\mathrm{mL}$. Urine creatinine was determined using the colorimetric Jaffé reaction, in which picric acid is used as a color reagent. The urinary calcium/creatinine (Ca/Creat) ratio was calculated [2].

Statistical analysis: Normality and variances homogeneity were evaluated using Shapiro Wilks test and Levene's test respectively. Data were expressed as mean \pm standard deviation or median [range], depending on their scale.

Sample sizes selection was based on a pilot study of 37 cases. The following parameters were used to estimate the mean CaI $(\mathrm{mg} / \mathrm{d})$ : precision level of $\pm 10 \%$ of the mean of pilot data $( \pm 60.0 \mathrm{mg} / \mathrm{d})$, 95\% confidence intervals (CI) and standard deviation (SD) from the pilot data $(276.5 \mathrm{mg} / \mathrm{d})$. Thus, a minimum sample size of $\mathrm{n}=82$ was calculated. To compare $25 \mathrm{OHD}$ serum levels $(\mathrm{ng} / \mathrm{mL}$ ) between the three categories of $\mathrm{CaI}$, the following set of parameters were chosen: power of 0.8 , significance of 0.05 , SD of $7.7 \mathrm{ng} / \mathrm{ml}$ (from the pilot data), difference to detect $7.0 \mathrm{ng} / \mathrm{ml}$ (from the pilot data). The minimum sample size obtained was 24 men per group. In analogous manner and using a power of 0.8 , a significance of 0.05 and data from the pilot study, the minimum sample sizes were estimated to compare CaI, serum 25OHD levels, D and M components, and PI between three categories of $\mathrm{CaI}$ and three categories of serum 25OHD levels. In all cases, the minimum sample size obtained did not exceed $n=40$ per group.

Chi-square test and ANOVA were used to detect differences in percentages and means, respectively. Nonparametric equality-ofmedians was used to detect differences in medians. Spearman'rank correlations coefficient was used to determine the strength between CaI, 25OH levels, tooth loss, caries, DMFT, PI and SI. Multiple linear regression models adjusted for differences in age, BMI and SI were applied to explore the magnitude of the relations between CaI/25OHD levels and PI, caries, DMFT index. Data were analyzed using the SPSS 19 package for Windows; a p-value $<0.05$ was considered as significant.

\section{Results}

\section{Anthropometric and biochemical parameters}

Anthropometric, biochemical, and nutritional parameters are shown in Table 1. None of the studied subjects had serum Ca, P, BAP, $\mathrm{CTX}$ levels or urinary $\mathrm{Ca} / \mathrm{Creat}$ ratio outside the reference range.

Although average BMI was within normal range, $11.2 \%$ of men were overweight and $18.7 \%$ of them were obese.

Median CaI was $619.4 \mathrm{mg} / \mathrm{d}$. Only $28 \%$ of men met the Ca recommendation of $800 \mathrm{mg} / \mathrm{d}$, whereas $24 \%$ had a CaI between 600 $800 \mathrm{mg} / \mathrm{d}$ and $48 \%$ had deficient $\mathrm{CaI}(<600 \mathrm{mg} / \mathrm{d})$. The mean $25 \mathrm{OHD}$ level was $25.3 \pm 1.9 \mathrm{ng} / \mathrm{mL}$. Only $29 \%$ of men had $25 \mathrm{OHD} \geq 30 \mathrm{ng} /$ $\mathrm{mL}$. About, the $71 \%$ of men with $25 \mathrm{OHD}$ levels $<30 \mathrm{ng} / \mathrm{mL}, 49 \%$ exhibited values between 21 and $29 \mathrm{ng} / \mathrm{mL}$, and $22 \%$ showed levels $<20 \mathrm{ng} / \mathrm{mL}$.

As compared to dietary recommendations, protein intake, expressed as $\mathrm{gr} / \mathrm{kg} / \mathrm{day}$, was higher than recommendations in $29 \%$ and lower in $21 \%$ of the studied men.

Because of the low CaI, the $\mathrm{CaI} /$ protein intake ratio was $9.9 \pm 1.1$, far lower than the $20 \mathrm{mg} / \mathrm{g}$ recommended for mineralized tissue health (Table 1).

\section{Lifestyle habits}

Sixty-five percent of men consumed soft drinks daily. The percentage of men that consumed soft drinks daily increased as CaI decreased. Indeed, $81 \%$ of men consumed soft drinks daily when $\mathrm{CaI}$ was $<600 \mathrm{mg} / \mathrm{d} ; 60 \%$ when CaI ranged between 600 and $<800 \mathrm{mg} / \mathrm{d}$; $33 \%$ when CaI ranged between 800 and $<1000 \mathrm{mg} / \mathrm{d}$, and $0 \%$ when CaI was $>1000 \mathrm{mg} / \mathrm{d}$.

Twenty five percent smoked, and 52\% of smokers smoked more than 10 cigarettes per day. Only $20 \%$ (CI 95: 9-29) ate fruit daily, and 15\% (CI 95: 5-24) ate no fruit at all.

\section{Dental status}

The results of the dental status evaluation are shown in (Table 2). The final M/T score of the total population was $2.9 \%, \mathrm{D} / \mathrm{T}$ score was $16.2 \%$, and $\mathrm{F} / \mathrm{T}$ score was $18.7 \% ; 41 \%$ of men were missing at least one tooth. The DMFT score of the total population was $11.4 \pm 0.9$. It must be pointed out that when considering the one third of the studied group with the highest scores of DMFT, its value reached to $17.4 \pm 0.5$. Strong cariogenic risk was observed in the studied men, as shown by the high PI $(1.9 \pm 0.2)$ and SI $(5.3 \pm 0.2)$ values. The high SI value indicates high consumption of fermentable carbohydrates and the PI $>1$ indicates inadequate dental hygiene and plaque control.

There was a negative correlation between $\mathrm{CaI}$ and caries ( $\mathrm{r}=-$ $0.447 ; \mathrm{p}=0.007)$ and missing teeth $(\mathrm{r}=-0.425 ; \mathrm{p}=0.017)$. PI correlated with caries $(\mathrm{r}=0.395 ; \mathrm{p}=0.012)$ and missing teeth $(0.359 ; \mathrm{p}<0.05)$. In addition, CaI/protein intake ratio correlated negatively with tooth loss $(r=-0.398 ; p=0.018)$. No correlations were found between 25OHD levels and the studied parameters; however, $100 \%$ of the studied men presented gingivitis.

Adjusted linear regression models were applied to explore the magnitude of relations between CaI, caries and missing teeth. Significantly negative associations (coefficient, $\mathrm{T}$ ratio; significance) were found between $\mathrm{CaI}$ and caries $(-0.449,-2.750, \mathrm{p}<0.01)$ or missing teeth $(-0.009,-0.425 ; \mathrm{p}=0.013)$, however no association was observed between CaI and DMFT or PI. 
Table 4: Mean values the decayed (D), Missing (M) and Filling (F) index (DMFT) and, D and M component as percentage of total teeth, Plaque Index Löe Silness (PI ), Sugar Intake (SI) and total teeth according to Ca intake and 25OHD levels in the studied men $(n=241)$.

\begin{tabular}{|c|c|c|c|c|c|c|}
\hline & \multicolumn{3}{|c|}{ Calcium Intake (mg/day) } & \multicolumn{3}{|c|}{25 OHD (ng/mL) } \\
\hline & $\geq 800$ & $800-600$ & $<600$ & $\geq 30$ & $21-29$ & $\leq \mathbf{2 0}$ \\
\hline & $-28 \%$ & $-24 \%$ & $-48 \%$ & $-29 \%$ & $-49 \%$ & $-22 \%$ \\
\hline D (DMFT) & $3.8 \pm 1.0$ & $2.0 \pm 0.8$ & $6.4 \pm 0.9^{* * *}$ & $4.2 \pm 0.8$ & $4.7 \pm 1.3$ & $4.8 \pm 0.7$ \\
\hline M (DMFT) & $0.3 \pm 0.2$ & $0.2 \pm 0.1$ & $1.8 \pm 0.5^{*}$ & $0.8 \pm 0.6$ & $1.3 \pm 0.5$ & $1.5 \pm 0.9$ \\
\hline F (DMFT) & $6.3 \pm 1.2$ & $6.2 \pm 1.1$ & $5.3 \pm 1.0$ & $5.7 \pm 1.8$ & $5.8 \pm 1.2$ & $6.1 \pm 2.0$ \\
\hline PI RV: $\leq 1$ & $1.5 \pm 0.2$ & $1.5 \pm 0.1$ & $2.2 \pm 0.2^{*, * *}$ & $1.8 \pm 0.5$ & $1.8 \pm 0.4$ & $1.6 \pm 0.2$ \\
\hline SI RV: $<4$ & $5.3 \pm 0.2$ & $5.4 \pm 0.1$ & $5.7 \pm 0.1$ & $5.2 \pm 0.3$ & $5.4 \pm 0.2$ & $5.5 \pm 0.2$ \\
\hline Total Teeth & $29.2 \pm 0.4$ & $29.0 \pm 1.1$ & $28.9 \pm 0.3$ & $28.6 \pm 0.9$ & $29.3 \pm 0.6$ & $29.1 \pm 0.8$ \\
\hline \multirow{2}{*}{ D/Total } & $7.10 \%$ & $6.90 \%$ & $18.8 \% \%^{* * *}$ & $19.10 \%$ & $17.80 \%$ & $16.20 \%$ \\
\hline & IC95:1.9-13.7 & IC95:2.4-13.5 & IC95:13.9-32.8 & IC95:10.9-28.7 & IC95:4.8-23.9 & IC95:3.1-23.2 \\
\hline \multirow{2}{*}{ M/Total } & $1 \%$ & $2 \%$ & $11 \%^{*, * *}$ & $0 \%$ & $1 \%$ & $3.8 \% \%^{\#, x}$ \\
\hline & IC95:0.0-3.9 & IC95:0.0-6.0 & IC95:4.1-14.5 & IC95:0.0-3.5 & IC95:0.0-6.6 & IC95:1.0-11.2 \\
\hline \multirow{2}{*}{ F/Total } & $9.50 \%$ & $15.80 \%$ & $18.2 \%{ }^{*}$ & $16.10 \%$ & $19.30 \%$ & $19.90 \%$ \\
\hline & IC95:3.2-9.5 & IC95:7.8-29.1 & IC95:13.1-30.8 & IC65:7.1-34.9 & IC95:8.0-24.7 & IC95:7.6-34.1 \\
\hline
\end{tabular}

D/DMF and M/DMF, PI, SI and total teeth are expressed as mean \pm SD. Data were analyzed by ANOVA two factors and Multiple Comparison test as a post hoc test. D/ total and $\mathrm{M} /$ total are expressed as percentage and they were analyzed by Chi-square test and Multiple comparison test as a post hoc test ${ }^{*} \mathrm{p}<0.05$ compared to Cal intake $>800 \mathrm{mg} / \mathrm{day}$; "* $<0.05$ compared to Ca intake $800-600 \mathrm{mg} /$ day; \# $\mathrm{p}<0.05$ compared to levels of $25 \mathrm{OHD}>30 \mathrm{ng} / \mathrm{mL}$;

${ }^{\mathrm{p}} \mathrm{p}<0.05$ compared to levels of $25 \mathrm{OHD} 21-29 \mathrm{ng} / \mathrm{mL}$.

Association between $\mathrm{Ca}$ intake/25OHD levels and biochemical parameters and dental status.

The men were divided into three groups of CaI and Vitamin D levels: adequacy, insufficiency and sufficiency. Biochemical parameters corresponding to the three analyzed $\mathrm{CaI}$ levels are shown in Table 3. Independently of Ca nutritional status, average serum $\mathrm{Ca}$, $\mathrm{P}$, and BAP levels and urinary $\mathrm{Ca} / \mathrm{creat}$ ratio were within reference ranges, and no differences in these parameters were observed among the three CaI groups. However, the levels of CTX tended to increase as CaI decreased without reaching statistical significance $(p=0.066)$. In addition, average $25 \mathrm{OHD}$ levels were below $30 \mathrm{ng} / \mathrm{mL}$ in the groups having a deficient and insufficient CaI.

Biochemical parameters corresponding to each of the studied 25OHD levels are shown in Table 3. Mean CaI were below $600 \mathrm{mg} / \mathrm{d}$ in the groups having a deficient and insufficient nutritional status of vitamin D. Moreover, irrespective of vitamin D nutritional status, no significant differences in the studied biochemical parameters were found among 25OHD groups. However, the highest no-statistically significant levels of CTX and PTH were observed in vitamin D deficiency $(\mathrm{p}=0.064)$.

Dental status parameters corresponding to CaI levels are shown in Table 4. The highest statistically significant value of the D and $\mathrm{M}$ components of the DMFT index, and of D, M and F expressed as a percentage of total teeth were observed in the CaI $<600 \mathrm{mg} / \mathrm{d}$ group $(\mathrm{p}<0.05)$. No differences in these parameters were observed between the two remaining $\mathrm{CaI}$ groups. The highest mean PI value was observed in men with $\mathrm{CaI}<600 \mathrm{mg} / \mathrm{d}(\mathrm{p}<0.05)$, suggesting that the men in this CaI group had worse oral hygiene and dental plaque control. SI was higher in deficient and insufficient CaI groups as compared to the adequate $\mathrm{CaI}$ group, although without reaching significance $(\mathrm{p}=0.059)$; no differences in SI were observed between the former groups.
Dental status parameters corresponding to each of the studied 25 OHD levels are shown in Table 4. Only M/T was higher in the group with $25 \mathrm{OHD}$ levels $<20 \mathrm{ng} / \mathrm{mL}$ as compared to the other studied groups $(\mathrm{p}<0.05)$. No significant differences in the remaining dental studied parameters were observed among the three $25 \mathrm{OHD}$ groups.

When the group with the highest caries score was compared to the rest of the men several differences in the study variables were observed. In this regard, comparison of the one third of the studied group with the highest DMFT scores (DMFT33\%: 17.4 \pm 0.5 ) with the remaining 67\% (DMFT67\% 8.1 \pm 0.6 ) showed that those with highest prevalence of dental caries (HPC) had significantly lower CaI $(657 \pm 49$ vs. $481 \pm 72 \mathrm{mg} / \mathrm{d}, \mathrm{p}=0.023)$ and $\mathrm{Ca} /$ protein intake $(10.9 \pm 1.2$ vs. $7.1 \pm 1.0 \mathrm{p}<0.05)$ than those with low prevalence of caries (LPC); however no significant differences were observed in protein intake $(1.11 \pm 0.39 v s .0 .98 \pm 0.51 \mathrm{~g} / \mathrm{kg} / \mathrm{d})$ or in $25 \mathrm{OHD}$ levels $(26.2 \pm 4.3 v s$. $22.9 \pm 3.1 \mathrm{ng} / \mathrm{mL})$. HPC men as compared to LPC subjects also showed significantly higher mean PI ( $1.8 \pm 0.1$ vs. $2.1 \pm 0.1 ; \mathrm{p}<0.05)$ and daily consumption of soft drinks ( $55 \%$ vs. $79 \%$; $\mathrm{p}<0.05)$ while SI almost reached significance $(5.1 \pm 0.2 v s .5 .5 \pm 0.1 ; \mathrm{p}=0.06)$.

\section{Discussion}

The group of young men studied here showed high cariogenic activity and severity of oral disease. The poor $\mathrm{Ca}$ and vitamin $\mathrm{D}$ nutritional status, the high $\mathrm{CaI} /$ protein intake ratio, the frequent intake of extrinsic sugar, and the high consumption of soft drinks might have contributed to the high dental caries activity observed in the studied men. The negative impact of the dietary factors became evident when comparing the $33 \%$ of men exhibiting significantly higher cariogenic activity and the remaining $67 \%$. Indeed, the group of men exhibiting the worst oral health had lower $\mathrm{CaI}$ and $\mathrm{Ca}$ /protein intake ratio, higher daily consumption of soft drinks, and higher plaque index. 
The severity and prevalence of caries was established with the DMFT score, commonly used in the dental practice. This score has continuously been used by the National Health and Nutrition Examination Survey (NHANES) to assess caries prevalence [29]. The overall mean DMFT score in the studied men was 11.4, with filled teeth accounting for around $50 \%$ of the dental caries experience. This value is almost two-fold the 6.6 DMFT score estimated for the Argentine population aged 20 to 30 years. This estimate arises from extrapolating the DMFT scores of 12-year-old children and 35-44year old adults published by the WHO oral health surveillance in 2003 [25]. Mean DMFT score increased to 17.4 in the 33\% of men corresponding to the group with higher cariogenic activity; the contribution of the F component was similar (50\%) to that observed in the whole population.

Several dietary habits may account for the high cariogenic activity observed in the studied men. Mean CaI was $619.4 \mathrm{mg} / \mathrm{d}$ [432.5-809.1], showing that a very high percentage did not meet dietary recommendation. In this regard, $72 \%$ of men had estimated average requirements (EAR) lower than $800 \mathrm{mg} / \mathrm{d}$, and $91 \%$ did not meet the recommended dietary allowance (RDA) of $1000 \mathrm{mg} / \mathrm{d}$. The percentage of men with poor Ca nutritional status rose to $78 \%$ and to $100 \%$, respectively, when analysing the third of the studied population with worse dental health. The low CaI observed here is certainly the result of low consumption of milk and dairy products, since these products provide the largest amounts of dietary Ca. This was not an unexpected finding: although there are no epidemiological studies conducted exclusively in young men, several national and international reports have shown inadequate $\mathrm{CaI}$ in adolescents and young adults. A review of several studies conducted between 1998 and 2006 showed insufficient CaI (approximately $500 \mathrm{mg} / \mathrm{d}$ ) in the Argentinean population associated with low consumption of milk and dairy products, independently of age and socioeconomic status [20]. The aforementioned review included the results of the National Survey on Nutrition and Health (ENNyS), which showed inadequate Ca intake in a high percentage of participants whose age was within the age range studied here [12]. A more recent study, the "Dairy consumption patterns in Argentina Population" conducted in 2009 in 1137 Argentinean adult subjects of both sexes (19-30 years of age) revealed that $65 \%$ of subjects did not meet the recommended dietary portion of milk or dairy products per day [30].

Over the last two decades, several researchers have reported a decrease in milk intake together with an increase in the consumption of soft drinks, suggesting that consumption of the latter has displaced consumption of milk [1]. The results of the present report evidenced such displacement, showing an inverse correlation between daily consumption of soft drinks and CaI. An important finding herein, was that the young men who covered RDA of Ca did not consume this kind of beverage daily. It is well known that an optimal $\mathrm{CaI}$ prevents alveolar bone loss, benefiting tooth retention [2,8]. Milk provides $\mathrm{Ca}$ and other components such as $\mathrm{P}$, lactose, and caseinphosphopeptides which enhance not only $\mathrm{Ca}$ absorption but also tooth health $[15,31]$. The concentrations of $\mathrm{Ca}$ and $\mathrm{P}$ in dental plaque are critical in terms of caries development, given the inverse relation between the concentrations of these ions in the plaque matrix and caries experience [32]. The increase in these components in plaque or saliva inhibits bacterial adhesion to enamel and bacterial biofilm formation [31], and enhances and decreases enamel remineralization and demineralization, respectively [33]. Two deleterious effects on tooth health may result from replacing milk with soft drinks: a change in the type of ingested sugar and an increase in the frequency of sugar intake. A high consumption of soft drinks increases the intake of free sugars or "non-milk extrinsic sugars" as opposed to the intake of lactose or "milk sugars". This change is potentially damaging to dental health because extrinsic sugars are potentially more cariogenic, whereas milk sugars have low cariogenicity and are cariostatic [6]. Fermentable sugars (glucose, sucrose, and fructose) induce major changes during the process of biofilm formation. Following intake of these sugars, the anaerobic metabolism of oral bacteria lowers the $\mathrm{pH}$ in the dental plaque and triggers a shift in the balance of resident plaque microflora to a more cariogenic one that reduces the $\mathrm{Ca}, \mathrm{P}$ and fluoride in the matrix of dental plaque, increasing susceptibility to caries development $[28,32]$. Whereas sucrose is the most cariogenic sugar, excessive exposure to fructose may also produce dental caries. However, according to reports, fresh fruit appears to be of low cariogenicity and citrus fruits have not been associated with dental caries. Moreover, it has been posited that increasing consumption of fresh fruit in order to replace 'non-milk extrinsic sugars' (free sugars) in the diet is likely to decrease the level of dental caries in a population [28].

The frequency of sugar consumption is also directly related to the prevalence of dental caries $[28,34]$. An increase in the frequency of exposure to carbohydrates results in the plaque being subjected to a prolonged period below the critical $\mathrm{pH}$ for enamel demineralization. This effect favors growth and selection of cariogenic bacteria, thereby enhancing demineralization. The very high SI and low consumption of fruit observed in the men studied here strongly suggest that sweeteners from soft drinks were eaten frequently during the day, increasing the overall length of time of exposure of teeth to sugars. Furthermore, although $60.1 \%$ of the studied men had a normal BMI, $18.7 \%$ had degree I obesity and $11.2 \%$ were overweight. A high BMI in healthy individuals may account for a high consumption of sugars, specially sucrose, and other carbohydrates. Moreover, a high BMI has been associated with poor oral health [7].

Dietary sugar changes the bacterial profile increasing the number of aciduric-bacteria. This type of microorganism can largely synthetize insoluble extracellular polysaccharides (EPS), which not only increase biofilm acidogenicity but also promote adherence of oral bacteria providing the biofilm with structural integrity and bulk. Dental plaque accumulation and poor oral hygiene are the two main overriding factors in the etiology of periodontal disease. Time must be a most important factor in considering plaque as an etiological risk-factor for caries and periodontitis [6]. In the present study, the men exhibiting deficient $\mathrm{CaI}$ had high plaque index values at the time of inspection. Plaque accumulation is an additional factor that would account for the high cariogenic status observed in the studied men who lived in a region where drinking-water is fluoridated.

Vitamin D is essential to Ca absorption and mineralization. The nutritional status of vitamin $\mathrm{D}$ is determined by the levels of $25 \mathrm{OHD}$, which in the present report were $25.3 \pm 1.9 \mathrm{ng} / \mathrm{mL}$. However, $71 \%$ of the studied men had an insufficient/deficient vitamin status D. This percentage is like the percentage of men who showed Ca inadequacy. It is well documented that chronically low CaI together with low 
25OHD levels have a deleterious effect on bone health, which would become manifest in adulthood. Ca and vitamin $\mathrm{D}$ are required to achieve optimal peak bone mass, which is not attained until the age of 25-30 years, the age range of the men studied here [1]. Both nutrients are also required in adulthood to reduce age-related bone loss. A low $\mathrm{Ca}$ and/or vitamin $\mathrm{D}$ nutritional status stimulates parathyroid hormone (PTH) release, the main factor causing the increase in bone resorption. In the present report, mean PTH and CTX concentrations were within reference values; however, the group of men with the lowest CaI and/or 25OHD levels presented the highest serum levels of both parameters suggesting a slight increase in bone remodeling. Systemic bone resorption would not only lead to bone loss overtime, increasing the risk of fragility fractures, but would also decrease alveolar bone mineral density (BMD), affecting tooth retention in the long term $[6,35]$.

Low serum levels of $25 \mathrm{OHD}$ have been reported to be a risk factor for periodontal disease [24]. Vitamin D may potentially influence periodontal risk by reducing oral inflammation and by promoting antimicrobial peptide production. Several researchers have suggested that to ensure these extra-skeletal effects, 25OHD levels should be higher than $30-32 \mathrm{ng} / \mathrm{ml}$ [11]. The results of the present report showed that $73 \%$ of the young men had 25OHD levels below 32ng/ $\mathrm{ml}$, suggesting that the immunomodulatory action of vitamin D was impaired. This high prevalence of vitamin D insufficiency was not unexpected, since it has been classified as an "epidemic" affecting different age groups, including young adults [11]. In the present report $100 \%$ of the studied men had gingivitis, suggesting a certain degree of inflammation. Although pocket probing depth was not assessed, the high level of both gingivitis and plaque accumulation suggests that onset of periodontitis was imminent.

The results of the present report showed that protein intake recommendation was met. Nevertheless, it must be kept in mind that protein protects bone health when CaI requirements are met [36,37]. The low CaI, observed in the present report decreased the CaI/protein intake ratio below the $20 \mathrm{mg} / \mathrm{g}$ required to protect mineralized tissues [32], adding yet another risk factor potentially affecting the subjects' oral health. In addition, the $\mathrm{Ca} /$ protein intakes ratio was even lower in the men exhibiting higher cariogenic activity.

It is well documented that smoking affects oral health [17]. The present study had too few smokers $(25 \%)$ to investigate the changes according to smoking status. However, $71 \%$ of smokers did not meet CaI recommendations, and 53\% had a deficient CaI. The latter men had more teeth affected by caries and $37 \%$ were missing at least one tooth.

\section{Limitations}

The limitations to the present report are the relatively small population of healthy men and the lack of information regarding many potentially confounding variables related to oral hygiene that may affect oral health. However, the number of missing teeth and high plaque index clearly evidence that the young men studied here had poor oral health. The strength of the present report is that all participants had a similar socioeconomic status, since a low socioeconomic status is a predisposing factor in the development of dental caries in adults.

\section{Conclusion}

The results of this cross-sectional report evidenced a low consumption of milk that along with a high daily consumption of soft drinks may account for the great severity of oral disease observed in the studied group of young men. Inadequate nutritional status of vitamin $\mathrm{D}$ together with certain dietary factors may contribute, at least in part, to the high cariogenic activity, one of the main risk factors of tooth loss. The findings of the present report underscore the necessity for several nutritional strategies to prevent caries development, and consequently tooth loss. Nevertheless, other additional factors must be considered in the prevention of dental diseases. In this regard, improving dental hygiene by encouraging tooth-brushing with fluoride-containing toothpaste is also an important tool to ensure caries prevention. These strategies would improve the quality of life by preserving the natural dentition and by preventing the development of bone pathologies

\section{Acknowledgment}

This paper was part of Olga Antonenko's Doctoral thesis presented at the School of Dentistry, Buenos Aires University, in partial fulfillment of the $\mathrm{PhD}$, degree requirements. The authors thank ISALUD University for allowing them to carry out this investigation, and Miss Julia Somoza for her technical assistance. This study was performed with the support of the Buenos Aires University grant UBACYT CO21 N² 20020100100320 and the CONICET.

\section{References}

1. Abrams SA. Normal acquisition and loss of bone mass. Horm Res. 2003; 60: 71-76.

2. Adegboye AR, Christensen LB, Holm-Pedersen P, Avlund K, Boucher BJ, Heitmann BL. Intakes of calcium, vitamin $D$, and dairy servings and dental plaque in older Danish adults. Nutr J. 2013; 12: 61.

3. Adegboye AR, Fiehn NE, Twetman S, Christensen LB, Heitmann BL. Low calcium intake is related to increased risk of tooth loss in men. J Nutr. 2010; 140: 1864-1868.

4. Ritchie CS, Joshipura K, Hung HC, Douglass CW. Nutrition as a mediator in the relation between oral and systemic disease: associations between specific measures of adult oral health and nutrition outcomes. Critical reviews in oral biology and medicine. Crit Rev Oral Biol Med. 2002; 13: 291-300.

5. Touger-Decker R, Mobley C. Position of the Academy of Nutrition and Dietetics: oral health and nutrition. J Acad Nutr Diet. 2013; 113: 693-701.

6. Adegboye AR, Twetman S, Christensen LB, Heitmann BL. Intake of dairy calcium and tooth loss among adult Danish men and women. Nutrition. 2012; 28: $779-784$

7. Benguigui C, Bongard V, Ruidavets JB, Sixou M, Chamontin B, Ferrieres J, et al. Evaluation of oral health related to body mass index. Oral Dis. 2012; 18: $748-755$.

8. Kashket S, DePaola DP. Cheese consumption and the development and progression of dental caries. Nutri Rev. 2002; 60: 97-103.

9. Krall EA, Wehler C, Garcia RI, Harris SS, Dawson-Hughes B. Calcium and vitamin D supplements reduce tooth loss in the elderly. Am J Med. 2001; 111: 452-456.

10. Zanetti M, Harris SS, Dawson-Hughes B. Ability of vitamin D to reduce inflammation in adults without acute illness. Nutr Rev. 2014; 72: 95-98.

11. Holick MF. Vitamin D and bone health. J Nutr. 1996; 126: 1159S-64S.

12. Argentina MdSdIN. Encuesta Nacional de Nutrición y Salud -ENNyS-2005. Documento de resultados. Ministerio de Salud de la Nación. 2007. 
13. Pellegrini GG, Gonzales Chaves MM, Fajardo MA, Ponce GM, Toyos $\mathrm{GI}$, Lifshitz F, et al. Salivary bone turnover markers in healthy pre- and postmenopausal women: daily and seasonal rhythm. Clin Oral Investig. 2012; 16: 651-657.

14. Forshee RA, Storey ML. Total beverage consumption and beverage choices among children and adolescents. Int J Food Sci Nutr. 2003; 54: 297-307.

15. Ha EJ, Caine-Bish N, Holloman C, Lowry-Gordon K. Evaluation of effectiveness of class-based nutrition intervention on changes in soft drink and milk consumption among young adults. J Nutr. 2009; 8: 50.

16. Moynihan PJ. The role of diet and nutrition in the etiology and prevention of oral diseases. Bulletin of the World Health Organization. 2005; 83: 694-699.

17. Hanioka T, Ojima M, Tanaka K, Matsuo K, Sato F, Tanaka H. Causa assessment of smoking and tooth loss: a systematic review of observational studies. BMC Public Health. 2011; 11: 221.

18. Christensen LB, Petersen PE, Krustrup U, Kjoller M. Self-reported ora hygiene practices among adults in Denmark. Community Dent Health. 2003; 20: 229-235.

19. World Medical Association Declaration of Helsinki: ethical principles fo medical research involving human subjects. The Journal of the American College of Dentists. 2014; 81: 14-18.

20. Ware J, Snoww K, Ma K, Bg G. SF36 Health Survey: Manual and Interpretation Guide. 1993

21. Ware J. SF-36 Health Survey update. 2001. 3130-3139.

22. World, Health, Organization. Global Database on Body Mass Index. 2004

23. Ross AC, Taylor CL, Yaktine AL, Del Valle HB. Dietary Reference Intakes for Calcium and Vitamin D. Washington DC: National Academy of Sciences. 2011.

24. Grant WB, B.J. B. Low vitamin D status likely contributes to the link between periodontal disease and breast cancer. Breast Cancer Res Treat. 2011; 128: 907.

25. PE P. Continuous improvement of oral health in the 21st century - the approach of the WHO Global Oral Health Programme. Geneva, Switzerland. The World Oral Health Report. 2003.

26. Bratthall D. Introducing the Significant Caries Index together with a proposa for a new global oral health goal for 12-year-olds. Int Dent J. 2000; 50: 378 384
27. Silness J, Loe $\mathrm{H}$. Periodontal disease in pregnancy II. Correlation between oral hygiene and periodontal condition. Acta odontologica Scandinavica. 1964; 22: 121-135.

28. Moynihan P, Petersen PE. Diet, nutrition and the prevention of denta diseases. Public Health Nutrition. 2004; 7: 201-226.

29. Dye BA, Tan S, Smith V, Lewis BG, Barker LK, Thornton-Evans G, et al. Trends in oral health status: United States, 1988-1994 and 1999-2004. National Center for Health Statistics Vital Health Stat. 2007; 11.

30. Carmuega E, Rovirosa A, ME Z. La población argentina necesita consumir más calcio. El calcio de los lácteos se aprovecha mejor. Sitio Argentino de Producción Animal: Centro de Estudios sobre Nutrición Infantil (CESNI). 2013.

31. Danielsson Niemi L, Hernell O, Johansson I. Human milk compounds inhibiting adhesion of mutans streptococci to host ligand-coated hydroxyapatite in vitro. Caries Research. 2009; 43: 171-178.

32. Paes Leme AF, Koo H, Bellato CM, Bedi G, Cury JA. The role of sucrose in cariogenic dental biofilm formation--new insight. J Dent Research. 2006; 85: 878-887.

33. Ferrazzano GF, Cantile $T$, Quarto $M$, Ingenito A, Chianese $L$, Addeo $F$. Protective effect of yogurt extract on dental enamel demineralization in vitro. Australian Dental J. 2008; 53: 314-319.

34. Moynihan PJ. Dietary advice in dental practice. Br Dent J. 2002; 193: 563568.

35. Stewart S, Hanning R. Building osteoporosis prevention into dental practice. J Can Dent Assoc. 2012; 78: c29.

36. Rodrigues HL Jr., Scelza MF, Boaventura GT, Custodio SM, Moreira EA Oliveira Dde L. Relation between oral health and nutritional condition in the elderly. J Appl Oral Sci. 2012; 20: 38-44.

37. Rodriguez-Rodriguez E, Navia Lomban B, Lopez-Sobaler AM, Ortega Anta RM. Review and future perspectives on recommended calcium intake. Nutricion Hospitalaria. 2010; 25: 366-374.
Austin J Dent - Volume 4 Issue 7 - 2017

ISSN : 2381-9189 | www.austinpublishinggroup.com

Zeni et al. (C) All rights are reserved
Citation: Antonenko O, Seijo M, Brito G, Gualtieri AF, Pellegrini G and Zeni SN. Low Calcium Intake and Hypovitaminosis D Negatively Affect Oral Health in Young Men. Austin J Dent. 2017; 4(7): 1093. 